\title{
EXPLORING THE POTENTIAL OF ANIMAL FATS AND VEGETABLE OILS AS POTENTIAL METAL CUTTING FLUIDS
}

\author{
B.U. ANYANWU ${ }^{1}$, D.A. FADARE ${ }^{2}$, O.S.I. FAYOMI ${ }^{3}$, P.O. AIYEDUN ${ }^{4} \&$ O. AGBOOLA ${ }^{5}$ \\ ${ }^{1}$ Research Scholar, Mechanical Engineering Department, Federal University of Agriculture, Abeokuta, Ogun State, Nigeria \\ ${ }^{1,2,4}$ Research Scholar, Mechanical Engineering Department, University of Ibadan, Oyo State, Nigeria \\ ${ }^{3}$ Research Scholar, Mechanical Engineering Department, Covenant University, Ota, Ogun State, Nigeria \\ ${ }^{5}$ Research Scholar, Chemical Engineering Department, Covenant University, Ota, Ogun State, Nigeria
}

\begin{abstract}
Conventional mineral based oils currently being used as metal cutting fluids are not environmentally friendly and pose health challenges to users. Therefore, there is need to formulate alternate cutting fluids that will not pose such challenges. Hence, this study was aimed at formulating and characterizing some selected vegetable and animal oilsas metal cutting fluids, for possible replacement of mineral based cutting fluids. The vegetable and animal oils were formulated into cutting fluids following procedures from published articles. Thereafter, the formulated fluids were characterized in terms of $\mathrm{pH}$, viscosity, fluidity, density and corrosiveness. Conventional mineral oil-based cutting fluid (MCF) was used as control in the study. The properties of the formulated fluids such as pH had an average value of 9, which is the standard value for most mineral based cutting fluids. Also, corrosion studies of the fluids showed that they cannot accelerate corrosion in machined components. This was evident from the results of the corrosive tests carried out, with corrosion rates ranging from $0.00040 \mathrm{~mm} / y$ rto $0.00082 \mathrm{~mm} / \mathrm{yr}$ for all the sample fluids. The results for density of all the sample fluids was between $0.9110 \mathrm{~g} / \mathrm{cm} 3$ to $0.9130 \mathrm{~g} / \mathrm{cm} 3$, while that of viscosity at $1000 \mathrm{C}$ was between $7.32 \mathrm{cSt}$ to $9.40 \mathrm{cSt}$. The results showed that the $\mathrm{pH}$, density, viscosity and fluidity of the sample fluids recorded competitive values with that of the control fluid. The best sample fluid with respect to all the properties obtained and compared with the control fluid (MCF) was LCF. This was followed by GCF, TCF, PKCF and POCF respectively. Hence, based on the characterization parameters studied, it was deduced that the sample fluid; having shared closed values with the conventional or control fluids, can be employed in cutting fluid formulation.

KEYWORDS: Mineral, Cutting Fluids, Animal Fats, Vegetable Oils, Cutting Tools
\end{abstract}

Received: Feb 04, 2020; Accepted: Feb 24, 2020; Published: Jun 26, 2020; Paper Id.: IJMPERDJUN202098

\section{INTRODUCTION}

Most parts of the world like Europe and Ushas instituted laws and regulations that appreciably affect the formulation of metal cutting fluids [1]. Industries using these fluids are relentlessly searching for better performing cutting fluids formulated from environmentally friendly materials. Also, most Governments, Industries and Employee Unions implement movements for a healthy and safe work environment, as well as disposal aspects influencing the global environment. These movements have already affected the formulation of cutting fluids in Europe and the US as follows: the removal of nitrite from cutting fluid composition and the replacement of diethanolamine short chained chlorinated paraffin $[1,2]$.

All these replacements have to be realized with the aim not to affect adversely the performance of the 
metalworking fluids. Cutting fluids are used in metal machining for variety of reasons and the result is to improve tool life, reduce work piece thermal deformation, improve surface finish and flushing away chips from the cutting zone [3]. In the 19th-century, machining practice was not uncommon to using plain water. This was a simple practice used to keep the cutting tool cool, regardless of whether or not it provided any lubrication at the cutting edge or chip interface. Although, when one considers that high-speed steel (HSS) had not been developed then, the need to cool the tool becomes very important $[4,5]$.

Cutting fluids are employed widely in most machining processes [6]. However, because of the damaging influences by some on the environment, their applications have been limited in machining processes. Modern approaches for elimination of cutting fluids application in machining processes have been examined in the past and "dry machining" was presented as an important solution [6, 7]. The development of new cutting tool materials also helped dry machining method to be a positive solution for cutting fluids applications. But the usage of cutting fluids has increased due to high production levels in the world. According to 1998 values, approximately $2.3 \times 10^{9}$ litres cutting fluids have been used in machining operations, costing about\$2.75 Billion. North America had a bigger consumption ratio, followed by Europe and the Asian Continent in that order $[9,10]$

Mineral oils have been in use as the traditional source of cutting fluids in machining a number of metals and alloys because of their suitable lubricating properties on both the work piece and the cutting tools [10]. However, there are now many challenges posed by using such oils as coolants in most of today's applications. Such challenges include, but not limited to the growing environmental concerns such as renewability and biodegradability [11]. Also, too much exposure or contact with it results to some health hazards. Vegetable and animal oil-based cutting fluids on the other hand, are environmentally friendly and do not pose any form of threat to health of the users. Recent studies have also shown that they have better lubricities than the mineral oil-based fluids [12]. Hence, considering the challenges connected with mineral based cutting fluids, the aim of this study was to formulate cutting fluids with some selected vegetable (groundnut oil, palm oil and palm kernel oil) and animal (pig fats and cow fats) oils, for possible replacement of mineral based cutting fluids.

\section{METHODOLOGY}

\subsection{Stage One: Cutting Fluid Formulation}

The palm oil, groundnut oil, palm kernel oil, pig fats (lard) and cow fats (tallow) were purchased from a local market in South west Nigeria. The palm oil, groundnut oil, and palm kernel oil (PKO) were already in form of oil, waiting for the actual cutting fluid formulation. The pig fats (lard) and cow fats (tallow) were washed and rendered into bits, and thereafter steamed without water in a pot for about 20minutes. This process extracted the oil from the fatty tissues of both animals, see (Figure 1). The oily content was then sieved out and allowed to cool for about 4 minutes. 

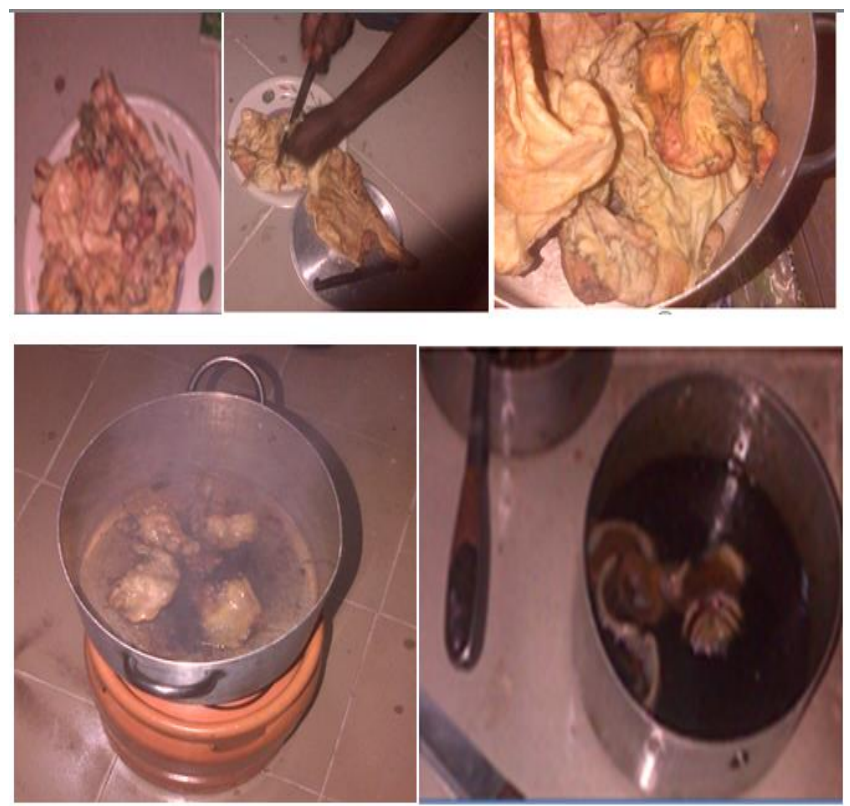

Figure 1: Tallow \& Lard Preparation.

The cutting fluids were then formulated following recommendations by $[10,11]$. Their recommendations are as specified on Table 1

Table 1: Cutting Fluid Emulsion Formulation

\begin{tabular}{|c|l|l|c|}
\hline S/n & \multicolumn{1}{|c|}{ Material } & \multicolumn{1}{|c|}{ Function } & $\begin{array}{c}\text { Content: \% Vol / } \\
\text { Vol of Fixed Oil. }\end{array}$ \\
\hline 1 & Fixed Oil (Sample fluids) & Base Oil & 80 \\
\hline 2 & $\begin{array}{l}\text { Emulsifier (see Table 2.2 for } \\
\text { composition) }\end{array}$ & Emulsification & 10 \\
\hline 3 & Phenolphthalein solution (phenol) & Disinfectant, also removes odor. & 5 \\
\hline 4 & Sulphur & $\begin{array}{l}\text { Extreme pressure agent improves oxidative } \\
\text { stability during usage at high temperature. }\end{array}$ & 5 \\
\hline
\end{tabular}

Table 2: Emulsifier Composition

\begin{tabular}{|l|c|}
\hline \multicolumn{1}{|c|}{ Item } & Composition \\
\hline Sodium lauryl sulphate & $0.5 \mathrm{M}$ \\
\hline Nitrosol & $0.5 \mathrm{M}$ \\
\hline Sodium tripolyphosphate & $0.5 \mathrm{M}$ \\
\hline Sulphonic acid & $0.5 \mathrm{M}$ \\
\hline Calcium carbonate & $0.5 \mathrm{M}$ \\
\hline Water & 5 litres \\
\hline
\end{tabular}

After following the composition stated in Table 2, a high-speed blender was used to homogenize the mixture at room temperature for 15 minutes to get emulsions. The emulsions were then mixed in water in a ratio of 1:10 [9-13] to get the cutting fluids (see figure 2) 


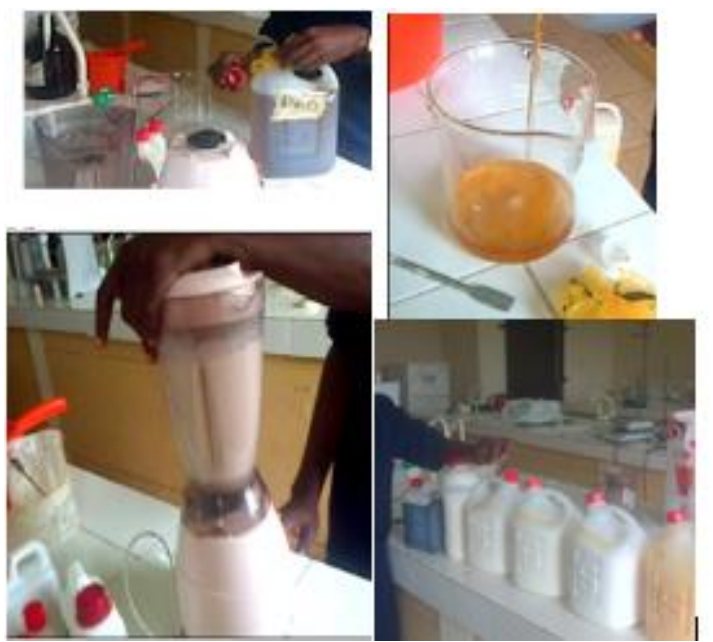

Figure 2: Formulated Cutting Fluids.

\subsection{Stage Two: Fluids Characterization}

The fluids were characterized in terms of the following properties:

pH: This was obtained with a wagtech digital $\mathrm{pH}$ meter. The measurement was done in accordance to NIST 2009 standards for $\mathrm{pH}$ measurements with $\mathrm{pH}$ meters. Before measurement, the $\mathrm{pH}$ meter was calibrated with a standard buffer solution (solutions of weak acids, weak alkaline, mixed with their respective salts). The device was dipped on the fluids for about 2 seconds and then removed. The $\mathrm{pH}$ values were then recorded.

Viscosity, $\eta$ : This was obtained with a viscometer (rapid visco analyzer with in-built temperature sensors).The measurement was done in accordance to ASTM D562-10 (2014) standard test for viscosity measurement with viscometers. The values were taken at $25^{\circ} \mathrm{C}$ and $100^{\circ} \mathrm{C}$.In the measurement, $5 \mathrm{ml}$ samples each of the fluids including that of the control, was placed on the glass ware provided in the viscometer. The temperature knob was set at $25^{\circ} \mathrm{C}$ and $100^{\circ} \mathrm{C}$ accordingly. The viscometer uses a rotating paddle at a fixed speed of 200rpm to directly measure the viscosity in Krebs units (KU), centipoises $(\mathrm{cP})$ or centistokes $(\mathrm{cSt})$. Measurement results were displayed instantly on screen after test in all three units.

Fluidity, $\gamma$ : This was computed directly from viscosity, i.e. the reciprocal of viscosity. Density, $\rho$ : This was obtained with a general-purpose hydrometer. The measurement was done in accordance to ISO 649-1: 1981 standard for density measurement with general purpose hydrometers. The device measures relative density values for fluids by using the principle of buoyancy. The relative density value is then multiplied by the density of water to give the density of each fluid. $5 \mathrm{~mL}$ each of the samples were placed in the graduated cylindrical beaker provided in the device. The hydrometer was then gently lowered into the fluid until it floats freely. The point at which the surface of the fluid touches the stem of the hydrometer correlates to the relative density.

Corrosiveness: This describes the protection of the machined components from corrosion after direct contact with the fluids during machining. Sizeable $(20 \mathrm{~mm}$ x $20 \mathrm{~mm})$ machined components made of mild steel was weighed with an electronic scale, and then immersed completely at room temperature in the test cutting fluids for 5days (120hrs). The components were then dried and weighed again, and the difference in weight was taken. Equation 1 by Fontana (1987) was then used to calculate the corrosion rates of the components. 


$$
C R=\frac{87.6 W}{\rho A T}
$$

$\mathrm{CR}=$ Corrosion rate $(\mathrm{mm} / \mathrm{yr}), \mathrm{W}=$ Weight loss $(\mathrm{g}), \rho=$ Density of mild steel $\mathrm{g} / \mathrm{mm} 3)$,

$\mathrm{A}=$ Exposed area $(\mathrm{mm} 2), \mathrm{T}=$ Exposure time $(\mathrm{yrs})$.

Cutting fluids color, odor and solubility: These were done by physical inspection during the formulation process.

\section{RESULTS AND DISCUSSIONS}

The results are presented side by side with the control fluid (MCF) to know which sample fluids best compares well with it. From Table 3, it is seen that the fluids had a pH value of 9 on the average. These values represent the standard $\mathrm{pH}$ for conventional MCF. The value is also in line with those reported by [13, 14].Hence, the fluids will not accelerate or cause corrosion in machined components when applied as cutting fluid. This is also evident from the results of the corrosive tests conducted on the sample fluids, (Table 4 ), which showed that all the samples recorded low corrosion rates. It is however important to note that, components during a typical machining operation may not be exposed in the cutting fluids up to the exposure time (120hrs) used for the corrosive tests in this study. Hence, less exposure time, means little or no corrosion with respect to exposure or contact with the cutting fluid, since the corrosion rates will further be reduced, more than what was obtained.

Table 3: pH Properties of the Cutting Fluids

\begin{tabular}{|c|c|}
\hline Sample Fluids & pH \\
\hline LCF & 8.98 \\
\hline TCF & 8.95 \\
\hline POCF & 9.10 \\
\hline GCF & 8.96 \\
\hline PKCF & 9.14 \\
\hline MCF & 9.19 \\
\hline
\end{tabular}

Table 4: Corrosive Properties of the Cutting Fluids

\begin{tabular}{|c|c|}
\hline Sample Fluids & Corrosion Rates $(\mathbf{m m} / \mathbf{y r})$ \\
\hline LCF & 0.00081 \\
\hline TCF & 0.00082 \\
\hline POCF & 0.00061 \\
\hline GCF & 0.00082 \\
\hline PKCF & 0.00040 \\
\hline MCF & 0.00020 \\
\hline
\end{tabular}

More so, the control fluid (MCF) had a density value of $0.9287 \mathrm{~g} / \mathrm{cm}^{3}$ at $25^{\circ} \mathrm{C}$ (Table 5). The formulated cutting fluids had their density values close to that of MCF. The values are also close to those reported by [13-16]. This implies that the formulated fluids can aid machine ability of the work piece just like MCF.

Table 5: Density Properties of the Cutting Fluids

\begin{tabular}{|c|c|}
\hline Sample Fluids & Density, $\boldsymbol{\rho}\left(\mathbf{g} / \mathbf{c m}^{\mathbf{3}}\right)$ at $\mathbf{2 5}^{\mathbf{}} \mathbf{C}$ \\
\hline LCF & 0.9127 \\
\hline TCF & 0.9130 \\
\hline POCF & 0.9132 \\
\hline GCF & 0.9110 \\
\hline PKCF & 0.9128 \\
\hline MCF & 0.9287 \\
\hline
\end{tabular}


The sample fluids also offered competitive fluidity values with that of the control. The samples fluidity Table 6) at high temperature was close to that of the control fluid (MCF). MCF had fluidity value of 0.113 rhes at $100 \mathrm{oC}$. LCF had the best fluidity values of 0.137 rhes at $100 \mathrm{oC}$ even when compared to the mineral oil (MCF). This means that even at temperatures above room conditions, the fluids can still flow to cover the entire machined metallic surface, thereby enhancing the cooling and lubricating capability.

Table 6: Viscosity and Fluidity Properties of the Cutting Fluids

\begin{tabular}{|c|c|c|c|c|}
\hline $\begin{array}{c}\text { Sample } \\
\text { Fluids }\end{array}$ & $\begin{array}{c}\text { Viscosity, } \boldsymbol{\eta}(\mathbf{c S t}) \text { at } \\
\mathbf{2 5}^{\mathbf{}} \mathbf{C}\end{array}$ & $\begin{array}{c}\text { Viscosity, } \boldsymbol{\eta}(\mathbf{c S t}) \text { at } \\
\mathbf{1 0 0}^{\mathbf{}} \mathbf{C}\end{array}$ & $\begin{array}{c}\text { Fluidity, } \boldsymbol{\gamma}(\mathbf{r h e s}) \text { at } \\
\mathbf{2 5}^{\mathbf{}} \mathbf{C}\end{array}$ & $\begin{array}{c}\text { Fluidity, } \boldsymbol{\gamma}(\mathbf{r h e s}) \text { at } \\
\mathbf{1 0 0}^{\mathbf{}} \mathbf{C}\end{array}$ \\
\hline LCF & 81.39 & 7.32 & 0.012 & 0.137 \\
\hline TCF & 86.12 & 9.36 & 0.012 & 0.107 \\
\hline POCF & 89.10 & 9.56 & 0.011 & 0.105 \\
\hline GCF & 80.51 & 8.89 & 0.012 & 0.112 \\
\hline PKCF & 82.55 & 9.40 & 0.012 & 0.106 \\
\hline
\end{tabular}

Table 7 shows the properties of the sample fluids physically inspected before and after emulsification. They were inspected during the formulation process.

Table 7: Physical Properties (Colour, Odour, Solubility) of the Oil Samples

\begin{tabular}{|c|c|c|c|}
\hline Samples & Properties & Before Emulsification & After Emulsification \\
\hline Lard & Colour & Dark & Milky white \\
\hline & Odour & Unpleasant, irritating & Slightly irritating \\
\hline & Solubility in water & Insoluble & Soluble \\
\hline Tallow & Colour & Dark & Milky white \\
\hline & Odour & Unpleasant & Slightly irritating \\
\hline & Solubility in water & Insoluble & Soluble \\
\hline Palm oil & Colour & Red & Pale yellow \\
\hline & Odour & Pleasant & Pleasant \\
\hline Groundnut oil & Colubility in water & Insoluble & Soluble \\
\hline & Odour & Gold & White \\
\hline & Solubility in water & Pleasant & Pleasant \\
\hline Palm kernel oil & Colour & Pale yellow & Insoluble \\
\hline & Odour & Pleasant & Pleasant \\
\hline & Solubility in water & Insoluble & Soluble \\
\hline
\end{tabular}

\section{CONCLUSIONS}

The study has shown the formulation and preliminary characterization of some animal (cow fats, pig fats) oils and vegetable (groundnut, palm oil, palm kernel) oils as metal cutting fluids. The oil samples were formulated successfully into cutting fluids following recommendations from some published articles. The properties considered for the characterization were few, reason why it was termed "preliminary characterization".

The following conclusion can be drawn from the study:

- The properties of the formulated fluids such as $\mathrm{pH}$ had an average value of 9 , which is the standard value for most mineral based cutting fluids. Hence, they cannot accelerate corrosion in machined components.

- This is also evident from the results of the corrosive test done.

For an exposure time of 120 hours (which is more than the machining time in which the fluid gets in contact with a workpiece in a typical machining operation), the formulated fluids recorded low corrosion rates on the machined 
components tested. This means that if they are fortified with anti-corrosion additives like the conventional mineral oil; their corrosion inhibiting properties will be improved.

- The samples also had good fluidity values compared to that of the conventional fluids, which would make it maintain its lubricating effect at temperatures above room values.

Although the actual performance evaluation of the formulated fluid was not done in this study, it has been taken care of in the part II of the study. The best sample fluid with respect to all the properties obtained and compared with the control fluid (MCF) was LCF. This was followed by GCF, TCF, PKCF and POCF in the order which they have appeared respectively.

Hence, based on the characterization parameters studied, it was deduced that the sample fluids, having shared closed values with the conventional fluids, can be employed in cutting fluid formulation, especially when fortified with complete additives used in conventional mineral oils.

\section{REFERENCES}

1. W. Bartz (2001). Ecological and Environmental Aspects of Cutting Fluids. Lubrication Engineering. 57: 13-16.

2. P.S Sreejith and B.K.A Ngoi (2000). Dry machining; Machining of the future. Journal of Materials Processing Technology. 101: 287-291.

3. T.F Glenn and F Van Antwerpen (1998). Opportunities and market trends in metal working fluids. Lubrication Engineering. 54: $31-37$.

4. S.B. Adejuyigbe, and S.P. Ayodeji, (2000). Soya bean Oil as an Alternative to Soluble Oil in Machining a Mild Steel Material. Nigeria Journal of Pure and Applied Physics. 1: 18-24.

5. S.A., Lawal, I.A Choudhury,.and Y. Nukman, (2011). Application of vegetable oil-based metal working fluids in machining ferrous metals-A review. International Journal of Machine Tools and Manufacture. 52: 1-12.

6. P.A.O., Adegbuyi, G., Lawal, O. Oluseye, and G. Odunaiya, (2010). Analysing the effect of Cutting Fluids on the Mechanical Properties of Mild Steel in a Turning Operation. American Journal of Scientific and IndustrialResearch. 2 (1): 1-10.

7. J.A. Akpobi, and W.O., Enabulele, (2002).Formulation of a water-soluble oil as a metal cuttingfluid, Nig. Inst. of Production Engineers Technical Transactions, Special Edition, 7(3),97-106.

8. R.F Avila and Abrao A.M. (2001). The effect of cutting fluids on the machining of hardened AISI 4340 steel. J. Mater. Process. Technol. 119: 21-26.

9. W.A.J. Chapman (1972). Workshop Technology. Edward Arnold Publishers Limited, U.K. 1:167 -191

10. E.P., DeGarmo, J.T., Black, R.A. Kosher(1984). Materials and Processes in Manufacturing. Maxwell MacMillan Publication, (7th Edition) New York, USA. 578-581.

11. M.M.A., Khan, M.A.H.,Mithu, N.R.Dhar (2009). Effects of minimum quantity lubrication on turning AISI 9310 alloy steel using vegetable oil-based cutting fluid. J. Mater. Process. Technol. 209: 5573-5583.

12. P. Krishna Vamsi, R.R., Srikant, D. Rao (2010). Experimental investigation on the performance of nanoboric acid suspensions in SAE-40 and coconut oil during turning of AISI 1040 steel. Int. J. Mach. Tool Manuf. 50: 911-916.

13. E., Kuram,B., Ozcelik, E.,Demirbas,E. Sik (2010). Effects of the cutting fluid types and cutting parameters on surface roughness and thrust force. Proceedings of the WCE 2010, London, UK. Vol. II, June 30-July 2, 2010. 
14. S.A., Lawal,M.S., AbolarinB.I., Ugheoke,E.O Onche (2007). Performance evaluation of cutting fluids developed from fixed oils. LEJPT 10: 137-144.

15. A.W.C, Menzies, W.Q, Kleinspehn, G.Q Lewis, and E.C Bingham (1922). Determination of specific heat, density, surface tension, viscosity and lubricating values of typical oils. National Bureau of Standards, U.S.A. 16:55-64

16. S., Sharif, N.M., Yusof,M.H., Idris,Z.B., Ahmad,I., Sudin,A., Ripinand M.A.H. Mat Zin (2009). Feasibility study of using vegetable oil as a cutting lubricant through the use of minimum quantity lubrication during machining. Research VOT No. 78055, Department of Manufacturing and Industrial Engineering, Faculty of Mechanical Engineering, UniversitiTeknologi Malaysia. http://eprints.utm.my/9729/1/78055.pdfS. 